\title{
Recently identified features that help to distinguish ceremonial tsantsa from commercial shrunken heads
}

\author{
Tobias M. R. Houlton ${ }^{1}$, Caroline M. Wilkinson²
}

\section{Abstract}

This is an anthropological investigation into a collection of 65 shrunken human heads, to determine if new characteristics can be identified to facilitate the differentiation between ceremonial tsantsa and commercial shrunken heads. Ceremonial tsantsa refers to shrunken heads mummified as war trophies within the ancient traditions and rituals of the Amazonian Shuar, Achuar, Awajún/Aguaruna, Wampís/Huambisa and CandoshiShapra (SAAWC). Commercial shrunken heads are comparatively modern objects constructed specifically for the collector market of the past. Low earning individuals in South and Middle America, outwith the SAAWC culture, who had access to corpses and appropriate medical or taxidermy provisions, produced these for trade purposes. These heads were made in abundance and do not present the same historical value or heritage as ceremonial tsantsa. The relevance of an accurate provenance for heads may directly impact museums, with regard to identifying the authenticity of a specimen and how they should handle any potential requests to return such artefacts to their cultural homes.

Complying with current anthropological standards, a total of 6 ceremonial tsantsa and 36 commercial heads were identified. Greater confidence is prescribed to the assignment of commercial heads as their morphological appearance is at odds with the highly standardised presentation of ceremonial tsantsa. Many indicated that the processor had access to modern resources such as gloves and fine suturing equipment, which were not typically available to the SAAWC. Since traders sometimes closely replicating ceremonial tsantsa when shrinking and decorating heads for trade, limited certainty can be prescribed to this category. Minor deviations in ceremonial design resulted in 23 heads being defined as ambiguous in origin.

Each head was examined by manual inspection, infrared reflectography (IRR), CT and microscopic hair analysis, with ten new differentiating characteristics identified.

\section{Research Aim}

South American shrunken heads in circulation today have either been produced within a tribal context for ceremonial purposes, or for the soul interest of commercial trade. A collection of 65 shrunken heads, taken from collections housed in the Science Museum (London, UK), Smithsonian Institute (Washington DC, USA), and Elgin Museum (Elgin, UK), have been accessed to investigate variables in morphological design and preparation. Existing criteria first categorizes the heads as ceremonial or commercial (Table 1), with the intention to ascertain other undocumented qualities that may be used to further differentiate them. Research findings will benefit scholars and Museum curators to understand the criteria for a correct distinction between ceremonial tsantsa and commercial heads. 


\section{Introduction}

Head shrinking was originally a renowned war trophy custom, where a full-scale human head was reduced typically to the size of a large orange. The skull was removed and the head trophy formed by manually 1 remoulding the mummified skin while retaining the scalp hair of the decapitated victim. There is physical 3 evidence of this custom once being performed in a ritualistic context by the tribal populous inhabiting the 5eastern montaña of Ecuador and northern Peru (the Shuar, Achuar, Awajún/Aguaruna, Wampís/Huambisa 6 fand Candoshi-Shapra - SAAWC), within the primitive conditions of the Amazonian rainforest. These ${ }_{9}^{8}$ specimens are referred to as 'ceremonial tsantsa' - tsantsa being the original cultural term for a shrunken 1ohead $[1,2,3]$.

11

12
13 From the mid 1800s, the European trade for ceremonial tsantsa expanded rapidly as the Victorian 7 14collectors of curios considered these to be objects of desire. The first documented emergence date of $58 \frac{15}{16}$ shrunken heads being produced specifically by outsiders for solely curio trade purposes was in $1872[1,4]$. 59 17Heads were procured from any accessible human subjects, with animal skins often used to produce 60 19counterfeits designed to resemble human shrunken heads. These were manufactured in abundance across 6120 much of South and Middle America, commonly by third world doctors, mortuary technicians and taxidermists, 5222 who had access to contemporary surgical materials and protective gloves [1,2,3]. These heads can often be 63 24distinguished from ceremonial tsantsa and are referred to as 'commercial shrunken heads' 25

5426

Accounts speculate that $80 \%$ of existing shrunken heads currently residing in museums and private $5528 c$ ollections, are commercially produced counterfeits made from human or animal remains $[5,6]$. The rarity of 66 39 ceremonial tsantsa makes them a desirable novelty. The origins of ceremonial tsantsa as war trophies 67 31produced for ritual practices, arguably gives them a conceptual value that surpasses the comparatively 5833 contrived commercial heads. Such heads being fraudulently manufactured by a relatively contemporary 6934 population, solely to generate a financial income. The provenance of such specimens may also impact how 7036 museums wish to undertake requests to return heads to their cultural home. Ceremonial tsantsa were likely of 7138 SAAWC persons and thus should be returned to one of the SAAWC authorities. Commercial heads could have 7239 originated from anywhere across South and Middle America, potentially complicating their repatriation.

42 Significant indicators, such as ear morphology, skin texture, microscopic hair structure and DNA have 7443 been recognised by anthropologists to distinguish human from animal remains with confidence $[2,7,8,9,10]$. 75 45Findings from anthropological and ethnological investigations has further established morphological features 647 and decorative ornamentation that can be used to distinguish human ceremonial tsantsa from human $77{ }_{4 \mathrm{c}}^{48}$ commercial heads, see Table $1[1,2,3,11,12,13]$. The aim of this investigation was to identify new 78 50preservation or morphological characteristics that may enhance future discrimination between ceremonial 7952 Tsantsa and commercial heads. This study incorporates manual inspection, infrared reflectography (IRR), 3053 computerised tomography (CT) and microscopic hair analysis. 


\begin{tabular}{|c|c|}
\hline Ceremonial tsantsa & Commercial shrunken head \\
\hline 1. Size approximately equal to a clenched human fist. & 1. Variable scale. \\
\hline $\begin{array}{l}\text { 22. Posterior median sutured incision. } \\
3\end{array}$ & 2. Variable incision locations. \\
\hline 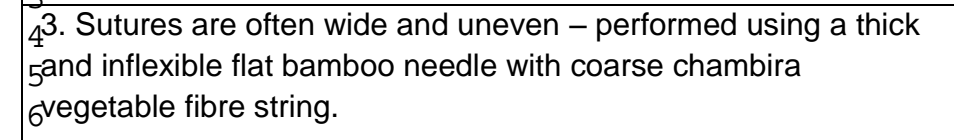 & $\begin{array}{l}\text { 3. Stitches are usually more precise, discreet and consistent - } \\
\text { due to access to finer, sharper, metal needles and thinner suture } \\
\text { threads. }\end{array}$ \\
\hline $\begin{array}{l}\text { 74. Loop of flexible vine is sewn into the neck - if absent, traces of } \\
8 \text { suturing are often evident. } \\
9\end{array}$ & 4. No supporting vine at the neck structure. \\
\hline $\begin{array}{l}10 \\
11^{5 .} \text { Eyelids are tightly drawn into the head and sutured shut. } \\
12\end{array}$ & $\begin{array}{l}\text { 5. Can be variable, but the eyelids are often sutured with the } \\
\text { upper lid positioned over the lower lid. }\end{array}$ \\
\hline $\begin{array}{l}\text { 136. Three mouth perforations from chonta pin application - } \\
14 \text { sometimes retained and lashed together with chambira. } \\
15\end{array}$ & $\begin{array}{l}\text { 6. No, or a variable number of perforations mark the mouth. If } \\
\text { pins are present, they are not always chonta wood. }\end{array}$ \\
\hline $\begin{array}{l}\text { 167. The mouth pins are classically replaced with intricately woven } \\
17 \text { string tassels applied to the mouth at a length equal to the scalp } \\
18 \text { hair. Several horizontal red bands of achiote are painted, but } \\
19 \text { hese can fade over time. }\end{array}$ & $\begin{array}{l}\text { 7. Tassels are often not attached. If present, atypical colourants, } \\
\text { materials and knots for securing them, may be present. }\end{array}$ \\
\hline $21^{8 .}$ Skin browned from carbon staining. & 8. Skin remains unstained, presenting as a grey or yellow colour. \\
\hline $\begin{array}{l}229 . \text { Facial down removed. } \\
23\end{array}$ & 9. Facial down is sometimes maintained. \\
\hline 2410. Skin is polished. & 10. Skin can sometimes present a dull, rough texture. \\
\hline $\begin{array}{l}25 \\
26^{11 .} \text { Narrow heads, often presenting a 'pinched' impression at the } \\
27 \text { temples. } \\
28\end{array}$ & $\begin{array}{l}\text { 11. Care was often taken to retain more natural proportions. The } \\
\text { curio trade was preoccupied with human heads, thus care was } \\
\text { taken to preserve its human appearance. }\end{array}$ \\
\hline $\begin{array}{l}29 \\
30 \text { mouth, and the spreading and upturning of the nose. } \\
31\end{array}$ & 12. Forced distortions were typically avoided. \\
\hline $\begin{array}{l}\text { 3213. Typically long scalp hair is present, with no facial hair. } \\
33\end{array}$ & 13. Scalp hair can vary in length. Facial hair is often maintained. \\
\hline 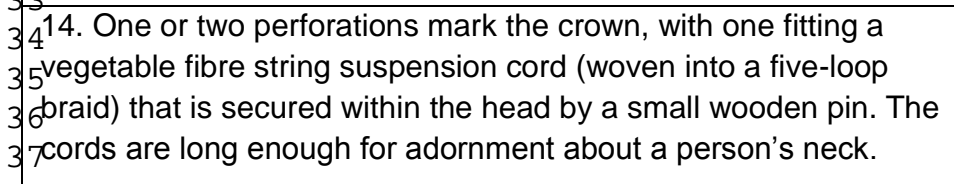 & $\begin{array}{l}\text { 14. Heads are not always perforated to fit a cord. If cords are } \\
\text { fitted, they can be produced from a variety of different materials, } \\
\text { woven differently, overly decorated and of an inappropriate } \\
\text { length for personal adornment around someone's neck. }\end{array}$ \\
\hline $\begin{array}{l}38 \text { 15. Piercings that would typically present at the earlobes of } \\
39 \text { SAAWC victims were not always decorated. Toucan feather ear } \\
4 \Theta_{1} \text { danglers and/or wooden tubes/pins are however common. }\end{array}$ & $\begin{array}{l}\text { 15. Headbands, necklaces and any ornamentation consisting of } \\
\text { beads, seeds, or portions of seeds, are not documented in } \\
\text { SAAWC material culture. }\end{array}$ \\
\hline $\begin{array}{l}4216 . \text { Skins tend to be dense and of considerable weight. } \\
43\end{array}$ & 16. Skins can sometimes be thin, fragile and lightweight. \\
\hline
\end{tabular}

A total of 65 shrunken human heads were accessed for this investigation - 44 came from the Science 35 59Museum (London, UK), 20 from the Smithsonian Institute (Washington DC, USA), and one from the Elgin $5{ }^{2}$ Museum (Elgin, UK).

53

$37 \quad 54$

55

38 56. Methods

58

3958 Each specimen was handled using latex rubber gloves to avoid further surface contamination. Investigative $0060^{6}$ techniques employed:

9162 . Manual inspection - details regarding the general morphology of the head and facial features were 64 
assessed for distortions and differences in their preparation. This included the location of handling compressions and the application of any sutures or other possible foreign materials.

To form the basis for discrimination and identify new patterns in ceremonial and commercial processing, the processing origins of each head were estimated according to the criteria defined in Table 1.

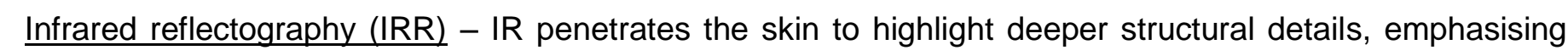
textural patterns in the tissue structure, including pathologies, scars and hair follicles [14].

To prepare each specimen for IRR image capture, heads were mounted temporarily over a stand, cushioned by white acid-free tissue paper. Hair was pushed back behind the ears carefully and secured with a regular metal hairpin, to enable maximum viewing of the facial details. To minimise perspective distortion during image capture, an optimal distance between a living subject and camera lens is typically recommended at $2 \mathrm{~m}$ [15]. Shrunken heads are however often reduced to approximately a fifth the size of an average adult head. Subject to camera distance was thus set to $0.5 \mathrm{~m}$ (quarter of the passport standard) to reduce the working space and strength of lens required, while still allowing for the moderately larger variations in shrunken head size to be photographed.

IRR was performed using a Fujifilm FinePix IS-1 camera, with a 28-300 mm zoom lens. An infrared lightemitting diode (IR LED) illuminated each head in a dark room, void of all natural light. To illuminate each face, the IR LED was positioned inferior to the camera lens and tilted slightly upwards towards the near parallel subject. An even light was cast with minimal shadow. An RG780 long pass transmission filter was applied over the camera lens. This reflected most of the visible spectrum and transmited much of the IR region that was longer than the $780 \pm 9 \mathrm{~nm}$ cut-off for image capture.

An ISO camera speed of $200+$ is recommended for IRR [16]. IR lighting was intense enough to maintain the ISO at 200 , avoiding a grainy image texture. The zoom lens was adjusted to $50-55 \mathrm{~mm}$ and the aperture set to $f-11$, to preserve depth of field. Using a RG780 filter, the camera required a longer shutter speed of $1 \mathrm{sec}$ to obtain adequate exposure. To avoid blurred images, the camera was mounted securely onto a tripod.

. Computerised tomography (CT) - a professional radiographer operated a Siemens SOMATOM Emotion CT scanner. This provided spiral $1 \mathrm{~mm}$ slices and a 3D reconstruction of all heads, which were scanned in transverse. Image size consisted of 512 × 512 pixels, offering a resolution sufficient for examining the general morphology of each head. Scans were presented as DICOM (Digital Imaging and Communications in Medicine) DCM files and viewed in OsiriX.

Due to limited facilities, CT scans were available for only 11 heads - comprising 2 ceremonial tsantsa, 6 commercial heads and 3 heads of ambiguous origin.

Microscopic hair analysis - used to examine the general condition of hair according to the prevalence of any identified diseases, disorders and traumas, hair treatments, sun bleaching, and the presence or damage caused by insects/arachnids or fungus $[7,8,9,10,17]$.

Permission to obtain a single strand of hair per head was obtained. These were taken directly from the scalp, using sterile tweezers and sharp scissors. Each strand was cut close to the root and placed into 
individually labeled, transparent resealable bags for safety and to avoid cross contamination. Longitudinal samples were prepared following protocols established by SWGMAT [18]. Where anomalies were identified, a section of hair (an inch minimum), was cut from the samples using sterile scissors. Tweezers positioned the hair on a glass slide. Samples were mounted using Styrolite ${ }^{\mathrm{TM}}$ [19]. All hair samples were viewed under a Leitz Wetlar ${ }^{\circledR}$ Orthoplan light microscope. In accordance with SWGMAT [18], the specimen field was illuminated with a low voltage tungsten filament lamp, and a colour correcting blue filter was used - ensuring samples were viewed in real colour. Relevant images were captured with Leica Application Suite software, using a DFC290 camera attached to the microscope.

\section{Results and Discussion}

Using current standards to identify processing origins, only $9 \%(6)$ heads could be comfortably assigned as

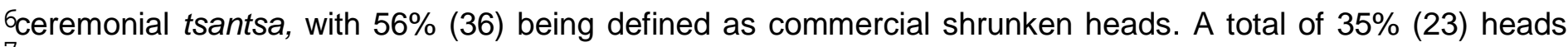
17

42 18were otherwise ambiguous in origin (Figure 1).

It was noted that commercial shrunken heads had the origin assigned with greater confidence than 1422 ceremonial tsantsa. This may be related to the fact that although some traders were faithful in replicating the

4523 techniques used by the SAAWC to shrink and finish heads, most were not [1, 20].

25

4626

27

4728

29

4830

31

32

The nature of the curio market and its influence on tribal behaviour also challenges the conceptual integrity 5033 f all heads assigned as ceremonial items. It is understood that SAAWC communities, in response to foreign 51 35trading influences and demands, were shrinking heads for reasons other than traditional religious interests.

$52{ }_{37}^{36}$ Available reports state that headhunters were also being commissioned by outsiders to shrink heads or even 5338 full bodies to bespoke requests, and possibly apply more decorative materials [1, 2, 3]. Therefore 35\% (23) 54 4cheads were defined as ambiguous for two fundamental reasons: 41

Figure 1: Distribution of ceremonial, commercial and ambiguous heads.

$31 \%$ of specimens appear ceremonial, but have atypical or ethnologically unreported materials attached (e.g. glass beads attached to earpieces). This implies that they were either produced commercially by a trader or a commissioned member of the SAAWC community, or were modified later.

$12 \%$ of specimens appear ceremonial, but possess minor physical anomalies that would have occurred pre-desiccation (e.g. no evidence of an incision made for skull removal). This implies that a trader or a commissioned member of the SAAWC community most likely produced them for commercial purposes.

\section{$52 \quad 55$.1. Compression patterns}

357 The original craniofacial structure collapses when the skull is removed from a head to enable shrinkage, 5459 thus manual manipulation is necessary to remodel the head shape. Ceremonial tsantsa can be characterised 55 61as having a long narrow face, sloping brow, an upturned and spread nose, with distended lips creating a 6662 receding chin and an elongated profile. Crucially during desiccation a shrunken head is hot, and the SAAWC 64 
used palm leaves to protect their hands. This often resulted in a strong depression being made from grasping the head at each temple, producing a laterally compressed and narrow forehead [1, 2, 21]. The analysis found that, consistent with previous findings, temple compressions affected $83 \%$ of ceremonial tsantsa and $83 \%$ Iambiguous heads. In addition to previous reports [1, 2, 21], there were regular compressions that affected the 3 lateral borders of the posterior head in $83 \%$ of ceremonial tsantsa, and $52 \%$ ambiguous heads. These type of ${ }_{5}^{4}$ compressions may have previously gone unidentified due to it being largely disguised by the scalp hair. Minor 6compressions were also typically identified across the cheeks or gonial regions.

7

In the ceremonial and ambiguous heads, the noses appeared spread and unnaturally upturned (close to a $1090^{\circ}$ angle), giving the nostrils more prominence and forcing the nasal bridge into a near horizontal angle. The

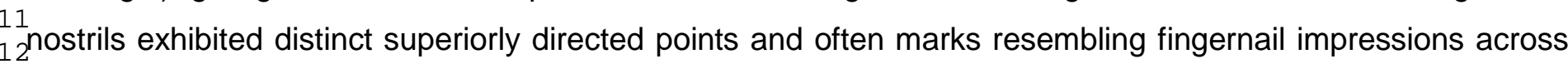

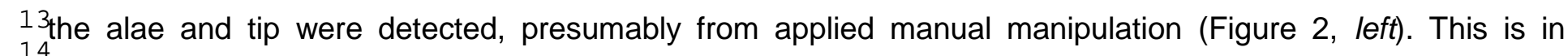
14 contrast to the commercial specimens, where only $43 \%$ heads presented only subtle pointing, with the rest 7916 maintaining a softer round or sometimes oval shaped nostrils (Figure 2, right). 18

3019

20 21 22 23 3324

25

3426

$35{ }_{28}^{27} d \mathrm{~d}$

Figure 2: Variation is nostril form - classically pointed nostrils of ceremonial tsantsa and typically rounded form of commercial heads

Commercial heads were more refined, with a more convincingly proportioned face and an upright profile, 36 29was rare, but heads sometimes presented a distinct dome with posteriorly placed ears, due to a section of skin 30

37 31being removed from the scalp to further reduce the overall head size. There were often no, or limited,

$38{ }_{33}^{32}$ compressions distorting the surface. Compressions unique to this category included:

34

$3935^{\circ}$

36

37

9138

39

7240

41

9342

43

9444

$22 \%$ with a marked pinching of the nose, which forcefully caused it to narrow and project to produce a more prominent profile - possibly from how the head was supported during desiccation or a product of Eurocentric design (nasal shape is purposely modelled to be more akin to Caucasoid type noses, rather than other ancestry groups).

$6 \%$ with a transverse compression lining the forehead, likely from how it was held during desiccation, causing the brow ridge to boss.

546

47

\subsection{Internal skin structure}

49

9750

51

An inspection of the deeper dermal tissues, viewed in cross-section, could only be performed via CT - a

8852 more detailed examination may however have been yielded by means of histological investigation (invasive) or

9953 micro-CT analysis (minimally-invasive). Sample size was limited and ideally all 65 heads would have

055 undergone CT analysis to further substantiate results. Upon viewing the scan, the dermal structure is the outer

01 57shell highlighted in white. A detachment in the papillary and reticular layer of the dermis was however evident

258 when the white skin structure is seen to divide, revealing a dark red void. This is a symptom best recognised

$360_{61}$ and researched by the leather industry, and is formerly referred to as 'double hiding' $[22,23]$. This feature was 4 62predominant in ceremonial (100\%) and ambiguous (67\%, with minor 'double hiding' presenting in 33\%) 564 specimens, where it is likely that stress had been placed on the skin to compress and distort its features by 65 
heavy handling and remodeling (Figure 3, left). The commercial heads were generally more refined in their morphological appearance, thus better conserving the dermal structure $(67 \%$ had minor signs of 'double hiding', 33\% had none) (Figure 3, right).

1

Figure 3: CT of a ceremonial tsantsa depicting the junctional splitting of the papillary and reticular layer (left), CT of a commercial head void of junctional splitting (right).

Double hiding can result from an imbalance of chemical and mechanical stress acting upon the dermal 10 issues [23]. During the desiccation of a shrunken head, heat is applied separately to the exposed superficial 11

15 12surface of the epidermis (or external papillary layer, if and when the epidermis has deteriorated) and internal

1613 reticular layer of the dermis. The heat then permeates through to the central dermal junction. An intense and

17 15rapid heat application may result in the collagen borders dehydrating and shrinking much faster than at the 1 junction, allowing moisture to become trapped. Hydrolysis may then occur, turning the junctional fibres of the 1918 dermis into gelatin [23]. The result is a structural weakness that can cause the papillary layer to detach from 20 20the reticular layer, which would be promoted by continual agitation and manipulation of the tissues when 21

21 22handling. Separation is thus emphasized where the skin is forced to distinctly arch out of normal alignment,

$22 \begin{aligned} & 23 \\ & 24\end{aligned}$

25

2326

27

24 285.3. External skin structure

29

2530 31

The contraction of facial tissues, results in the compaction and shortening of hair follicles into a smaller 26 32surface area, thus causing all hair to appear denser and longer than in life [24]. This includes the fine, peach2733 white hypopigmented, nonmedullated vellus hairs that ordinarily cover most of the body and constitute facial 28 35down. The facial skin presents a remarkably elevated concentration of follicles in the postcranial anatomy, 36

2937 specially across the nose [25, 26, 27]. In living subjects, only $2-3 \mathrm{~mm}$ of the vellus hair is exposed on the skin $30{ }_{39}^{38}$ surface [28]. Following shrinkage, this hair becomes more obvious if not removed. The longest downy hair 3149 dentified in this research measured approximately $8 \mathrm{~mm}$ in length.

41

42
43 Consistent in all ceremonial and ambiguous specimens, and identified in only $31 \%$ of the commercial

33 44heads, is the removal of facial down to reveal a smooth, refined and more polished skin texture. Any surviving 45

34 46downy hairs often being identified in inaccessible, tightly creased regions of the skin. Using IRR, a fluctuation

3548 in the epidermis was frequently presented across the facial skin, which correlated with the pattern in removal

36 49f downy hair (Figure 4, left). Flat, less resistant surfaces across more prominent regions of the face appeared 50

$3751^{\text {to }}$ have the epidermis removed. These regions would have been well suited to prolonged heat treatment and

3852 friction from the likes of a hot pebble, traditionally used to cure a shrunken head and rid it of facial down. Less

3954 significant regions of the head, primarily the neck, and hard to reach areas where the skin folds, alternatively

40 5had the remains of a blistered epidermis retained and possible evidence of downy hair. This was with

4157 exception to $14 \%$ commercial heads and $4 \%$ ambiguous heads, where the full epidermis was successfully

42 59removed. To achieve this finish, it is possible that a finer heat-bearing implement was used to access tighter 60

43 61regions of the face.

62

4463

64

65 
Figure 4: Commercial head with retained epidermis and facial down (left). Ceremonially styled ambiguous head, with actively removed facial down and alternating regions of epidermal degeneration across the face (right).

1 The cause for epidermal degeneration is estimated to be a result of direct heat application to the 3superficial skin during desiccation. This would be expected of ceremonial tsantsa, where a hot flat-edged ${ }_{5}^{4}$ pebble was classically employed to iron the superficial skin and remove facial down. The applied heat would Ghave penetrated the tissue surface, intensifying when it contacts and melts the natural oils that have a low 8melting capacity, promoting thermal damage to the skin. These oils subsequently ooze from the facial pores to 19 provide a smooth, slippery surface, ideal for gliding a hot implement over to continually iron the facial skin. The

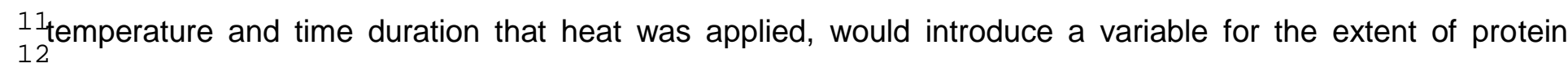
13 denaturation, cell damage, and surface contraction that occurred. This appears to have often resulted in not 14 only the removal of hair, but also the blistering and flaking of the thinner and weaker epidermal layer, 16 aggravated by the physical abrasion from the

18 heat-bearing implement used.

20

5921 Significant to $64 \%$ of commercial heads, was the near complete preservation of the epidermis (minor

$60 \begin{aligned} & 22 \\ & 23\end{aligned}$

61 24unkempt surface finish. This implies that direct heat treatment was either not applied to the face or very weakly

62 26applied at a low temperature and/or for only a limited time period, to create minimal or no impact (Figure 4,

6327 right). Among these, only $17 \%$ of heads appeared to retain full facial down. Most otherwise presented a coarse

5429 elt texture, where the downy hair appears to have been trimmed or shaved to reveal the skin. In $8 \%$ of the 30

55 31commercial heads, an epidermis was retained, but no evidence of downy hair was presented. This was

6632 presumably a consequence of wear and tear, possibly from frequent handling and bacterial activity, or the

67 34result of more careful facial down removal techniques using heat.

35

$68 \begin{aligned} & 36 \\ & 37\end{aligned}$

69 38(e.g. Figure 4, left), while commercial heads sometimes failed to have this performed and so retained their

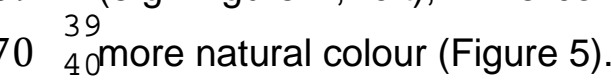

41

7142

43

7244

734

46

7447

48

It was evident that areas where the epidermis was present, often displayed a deeper, darker colouring to

7549 those where it had been lost. Epidermal degeneration likely occurred in the event of heat treatment at

$76{ }_{51}^{50}$ desiccation, not following it. The deeper colouring of the epidermis in contrast to the dermal tissues implies it

77 52has had the most prolonged exposure to carbon and also suggests that these tissues were possibly coloured 53

78 54during the desiccation phase when the epidermis was actively worn away, not following - otherwise a more

7955 consistent colouring would be expected. Alternatively, the epidermis is a comparatively weaker structure when

3057 compared with the dense interwoven collagen fibres of the dermis, possibly making it a more susceptible

31 59surface for colour absorption [23]. Negating this theory however are two ambiguous specimens, which have

3260 achieved a considerable deep dark brown colouring across both the epidermis and dermis. This would likely

336 be related to a more intensified exposure to carbon possibly during or following desiccation. To understand the 64influences of carbon staining upon the epidermis and dermis and attempt to overcome the conflicts in 65 


\subsection{Preservation and conservation material application}

Pitch was seemingly identified to preserve, conserve, disguise damage, and improve the aesthetic finish of heads. $67 \%$ of ceremonial tsantsa used this to secure toucan feather pendants to ear danglers, and in one ${ }_{2}^{1}$ case to fill a disused secondary suspension cord perforation at the crown of the head. In $58 \%$ commercial 3 heads and $52 \%$ ambiguous heads, pitch was used more eclectically (e.g. to disguise damage and incisions, splug orifices, coat the eyelids and attach miscellaneous ornaments directly onto the skin). Notably due to the ${ }_{-}^{6}$ properties of pitch as a waterproof substance that can also inhibit microbial activity owing to the terpenoids it $\varepsilon_{g}$ comprises, the use of pitch can evidently be acquainted to many different cultures, in different regions of the 1eworld, in various historic contexts [31,32]. Varnish coated the skin in only one ambiguous head. This was 11 likely to promote long-term preservation, improve hygiene, and arguably enhance the aesthetic appearance of 213 mummified remains [33]. Red pitch was also applied to protect and conceal damage in only one ambiguous 3 15head. Cotton (28\% commercial heads and 13\% ambiguous heads) and paper materials (11\% commercial

7416 theads and $4 \%$ ambiguous heads) were sometimes applied to cushion and fill the head's cavity. 18

7519 Foreign materials could have easily been applied by a secondary body and are not necessarily appropriate $6{ }_{21}^{20}$ evidence of a head coming from either ceremonial or commercial origins. In most cases, museum 7722 conservators, traders and private collectors, likely applied the various materials. It is however possible that the 78 24SAAWC solely used pitch on ear pendants or to fill a secondary suspension cord perforation in ceremonial

$79 \begin{aligned} & 25 \\ & 26\end{aligned}$ 27

3028

31305.7 Hair condition

31

3232

32

All ceremonial tsantsa and ambiguous heads present a distinctive long hairstyle, predominantly cut into 33 34three level tiers - influencing the fringe, temples and posterior scalp hair. This style is consistent with SAAWC $34 \begin{aligned} & 35 \\ & 36\end{aligned}$ fashions [1, 3].

37

3538

Commercial heads tended to present particularly short or long hair, with no consistent styling performed $6{ }_{40}^{39}$ one commercial head had however falsely applied hair to create a more hairy scalp texture. These heads were 374 likely taken from a populous residing in the more cosmopolitan towns, where fashions would be more varied. 42

43
44 Facial hair is notably uncommon across the collection. Moustaches or beards were extremely rare among 39 45the indigenous population of South America. This population present a sparse growth and development of 46

004 facial and body hair, and most Indian groups also perceived this hair as ugly and were likely to remove any 1148 34]. In contrast, Whiffen [35] often observed the prevalence of facial and body hair growth being a 22 6fundamental quality, significantly for those entering into and practicing shamanism across much of the North51 West Amazonas (potentially including the SAAWC, although this is not stated).

53

9454 In the ceremonial tsantsa and closely ceremonial resembling ambiguous heads, all or most being likely 556 produced from SAAWC or other indigenous victims, facial hair was rare. Moustache hair was however present $9657_{\text {in }}$ one ceremonial tsantsa and four ambiguous heads. These may have been shamanistic bodies from enemy 77 59communities, if not outsiders to traditional indigenous cultures. The moustaches were consistently cropped 9860 short and intermittent in pattern (e.g. Figure 8). The hot stone applied to iron and cure the outer skin during 9962 desiccation, and singe away the soft facial down, was presumably hot enough to burn and shorten the 00 64moustache hair to its given length - evidence included a few intermittent hairs presenting round vacuoles at 65 
01 the ends. The chonta pins, which fastened the mouth during shrinkage and desiccation, would have obstructed access to the full upper lip. This explains the confined circles of hair that remains surrounding the mouth's perforations. It is thus possible that the removal of facial hair, as with facial down, was intentionally practiced 1by the SAAWC. The purpose, whether it be for aesthetics or superstition, are uncertain.

2

3

4

Figure 8: Intermittent moustache hair surrounds pin perforations about the mouth of a ceremonial tsantsa.

Comparatively, facial hair would have been more fashionable among the colonial or colonised gtownspeople, and presented in $28 \%$ of commercial heads likely produced from such subjects. Styles included $10_{11}$ sideburns, moustaches, soul patches and full beards. The hair had a more defined presence than the 12ceremonial type specimens, with post-mortem shrinkage causing the hair to appear long, untamed and bushy, 13

114 unless combed and trimmed.

15

1216

$13 \begin{aligned} & 17 \\ & 18\end{aligned}$

14 19infections (from Phaeohyphomycosis) or fractures (Trichorrhexis nodosa and Central trichoptilosis) in the hair 20

15 21shaft are ante-mortem or post-mortem. Evident cases of Pediculosis humanis capitis De Geer and hair casts

1622 are however only acquired on living subjects, due to a dependence on a living blood supply and active hair

1724 growth [36, 37].

1826 Sun bleaching predominantly affected $67 \%$ of ceremonial tsantsa (in contrast to $42 \%$ commercial heads

1928 and $48 \%$ ambiguous heads), creating a contrasting colour difference between underlying and superficial hairs. 29

20 3๑All affected hairs were positioned towards the head's vertex - the point most exposed to direct sunlight when

2131 an individual is postured in an upright position. These heads would have in life and possibly death, been

2233 exposed to the outdoors and intensive sunlight for extensive periods of time. 34

35

36

2437

38

2539

40

2641 Rare, but significant to $17 \%$ of ceremonial tsantsa, and $13 \%$ of ambiguous heads that closely align with

2742 ceremonial appearance, was the presence of black piedra (Trichomycosis nodularis). This forms irregular dark

28 44brown-black nodules that colonise the hair shaft (Figure 9). The nodules consist of ascostromata, the hyphae 45

29 46and fruiting bodies of the fungus, from which fungal spores are released. It is an infection typically affecting

$30{ }_{48}^{4}$ scalp hair and is often asymptomatic. In severe cases it may cause the hair shaft to become brittle and break.

31 49Black piedra is caused by the dematiaceous filamentous fungus piedraia hortae - identified in soil and 50

3251 common in tropical areas, especially the rainforests of Malaysia and the Amazon of South America [38, 39,

335240 . Black piedra thus signifies individuals that may have lived or were maintained in death, in the Amazon

3454 rainforest - this most likely being the SAAWC populous. 55

3556

57

3658

Pediculosis humanis capitis De Geer, in the form of nits (Figure 10), were predominantly and more Figure 10: Microscopic view of a Pediculosis humanis capitis De Geer nit.

3963 profusely identified in $33 \%$ of commercial specimens, with minor intrusions only evident in $9 \%$ ambiguous 65 
heads. De Souza et al. [17] noticed a similar pattern when assessing five shrunken heads held by The National Museum, Rio de Janeiro, Brazil. Two heads were commercial with evidence of profuse nit infestation, two were ceremonial with no or few nits, and the fifth was not human. In agreement with de Souza et al. [17], 1the difference is likely related to the living condition in which the victims once existed. The ceremonial heads 2 3 would have been taken from indigenous SAAWC peoples, who were preoccupied with grooming and existed in ${ }_{5}^{4}$ a spacious, open environment. Commercial specimens would have presumably come from those who survived Gin poor slum settlements, where overcrowding and the rapid spread of infestation and disease were common 7 $8[17,41.42]$.

9

810 Evidence of possible disease, disorders or trauma was uncommon. Fractures in the hair shaft were 4911 however identified in $6 \%$ of commercial heads and were possibly the result of stressed styles, excessive 013 combing, intensive heat exposure, or congenital disorders. Only $4 \%$ of ambiguous heads also presented hair 15 casts, which can form in conjunction with various fungal skin infections or persistent and regular traction of the 1 thair.

54 216. Conclusion

A total of $65 \%$ shrunken heads were classified confidently by origin. $56 \%$ were commercial, demonstrating 56 25the popularity of shrunken head manufacture among traders. Only $9 \%$ were defined as ceremonial tsantsa. $57{ }_{27}^{26}$ The remaining 35\% heads presented some ambiguity and could not be classified with any degree of 5828 confidence. This was predominantly due to atypical superficial applications applied post-desiccation, and $5930 s o m e t i m e s$ physical anomalies that were incurred pre-desiccation.

31

6032 It is challenging to confirm heads as ceremonial tsantsa. Traders sometimes produced commercial heads 5134 to closely resemble ceremonial tsantsa. The concept of all SAAWC tsantsa, being defined as 'ceremonial,' $62{ }_{36}^{35}$ may also be debated. The popular business of exchanging a head for a gun, or other European material, 53 37meant SAAWC head-hunters sometimes became removed from the ceremonial intentions of head shrinking to 38

543 gfocus purely on expanding profits. The SAAWC were also open to commissions, encouraging the production of $654{ }_{41}^{40}$ atypical ceremonial tsantsa for western markets [1, 2, 3].

According to the detailed assessment performed on the defined ceremonial and commercial specimens, a $744^{4}$ series of new distinguishing features have been identified. These are stated in Table 2 . In addition to current 58 46findings, it is evident that unstained skins also present as a yellow colour when the dermis is exposed, and a

5948 grey-white when the epidermis is retained. This has previously gone unidentified.

49

7050

51

71 52Table 2: New distinguishing features, and how they contrast, for ceremonial tsantsa and commercial shrunken heads. 53

\begin{tabular}{|c|c|}
\hline 54 Ceremonial tsantsa & Commercial shrunken head \\
\hline $\begin{array}{l}5 \$ 1 \text {. Long narrow face, sloping brow, upturned \& spread nose, with } \\
57 \text { distended lips creating a receding chin and an elongated profile. } \\
5 \$ \text { Distinct compressions at the temples and lateral margins of the } \\
59 \text { posterior head. }\end{array}$ & $\begin{array}{l}\text { 1. More convincingly proportioned face and an upright profile. } \\
\text { Rounded to domed shaped scalp. }\end{array}$ \\
\hline 67 2. Superiorly pointed nostrils. & 2. Nostrils retain a more naturally rounded shape. \\
\hline $\begin{array}{l}62 \\
63 \\
64\end{array}$ & $\begin{array}{l}\text { 3. Minimal to no division of the papillary and reticular layer of the } \\
\text { dermis. }\end{array}$ \\
\hline
\end{tabular}




\begin{tabular}{|l|l|}
\hline 4. Epidermal degeneration across prominent regions of the face. & 4. The epidermis retained. \\
\hline 5. Removal of facial down. & 5. Facial down shaved, creating a stubble texture. \\
\hline 6. 'Over and over' sutures. & $\begin{array}{l}6 . \text { A variety of suture techniques. 'Baseball' sutures are most } \\
\text { common. }\end{array}$ \\
\hline $\begin{array}{l}\text { 7. Necks with supporting neck ring removed, demonstrating a } \\
\text { smooth and even inferior edge at the opening. }\end{array}$ & $\begin{array}{l}\text { 7. No neck ring and an uneven or irregular neck base edge. The } \\
\text { edging of the neck may be flayed or have pitch/resin applied. }\end{array}$ \\
\hline 8. Limited evidence of conservation and preservation materials. & 8. A variety of materials for conservation and preservation. \\
9. Scalp hair resembling long hairstyle, predominantly cut into \\
three level tiers - influencing the fringe, temples and posterior \\
scalp hair.
\end{tabular}

7214

15

16

$73 \quad 17$
18

18

$74 \quad 19$

20

$75 \quad 21$

22

7623

24

$77 \quad 25$

26

27

$78 \quad 28$

29

7930

31

$30 \quad 32$

33

3134

35

$32 \quad 36$

37

$33 \quad 38$

39

34 4๑Acknowledgements

41

35 43 Many thanks to the Centre for Anatomy and Human Identification at the University of Dundee (UK), where the

36 44research was predominantly conducted. Gratitude is also paid to the Smithsonian Institute (Washington DC,

45

$37{ }_{46} \mathrm{USA}$ ), The Science Museum (London, UK) and Elgin Museum (Elgin, UK), for permitting access to their

$38 \quad 47$ collections.

49

$39 \begin{array}{r}49 \\ 50\end{array}$

51

9052

53

9154

55

56

57

58

9359

60

9461

62

9563

64

65 


\section{References}

1. M.W. Stirling, Historical and Ethnographical Material on the Jivaro Indians, Smithsonian Institution Bureau of American Ethnology: Bulletin 117, Washington: Government Printing Office, 1938.

1

22. J.L. Castner, Shrunken Heads. Feline Press, Gainesville, F.L. USA, 2002.

3

43. M.J. Harner, The Jivaro: People of the Sacred Waterfalls. Berkeley, Los Angeles, London: University of California Press, 1972.

${ }_{8}^{7}$. R.A. Philippi, Menschenköpfe als Trophäen bei wilden Völkern, Globus, Band 1872, xxi, 340-3.

95 .

K.C. Duncan, 1001 Curious Things: Ye Olde Curiosity Shop and Native American Art, University of Washington Press (2001) 146-7.

C. Morgan, Object of the month: shrunken heads (real and fake), Wellcome Trust, http://blog. wellcomecollection.org/2014/06/27/object-of-the-month-shrunken-heads-real-and-fake/, accessed: 27 June 2014.

P. Charlier, I. Huynh-Charlier, L. Brun, C. Herve, G. Lorin de la Grandmaison, Shrunken head (tsantsa): A complete forensic analysis procedure, Forensic Science International (2012) 222:399.e1- 399.e5.

D. Hermon, R. Gafny, A. Zamir, L. Hadas, M. Faerman, G. Kahila Bar-Gal, The genetic signature of a shrunken head. Archaeological Anthropological Sciences 3 (2011) 223-8.

B. Reichenpfader, W. Buzina, P. Roll, The Mystery of Shrinking Heads. Journal of Forensic Science International Supplement Series 1 (2009) 22-23.

. A. Sauvageau, C. Kremer, V. Brochu, F. Julien, S. Racette, Jivaro Tsantsas or Shrunken Head. An Expertise of Authenticity Evaluation. The American Journal of Forensic Medicine and Pathology 30 (1) (2009) 72-4.

1. R.W. Mann, B.B. Farmer, J.W. Verano, South American shrunken heads: Genuines and fakes, Bioantropologia 2, 813.

12. G.L. Mutter, Jivaro tsantsas, authentic and forged: a study of two shrunken heads in the Mutter Museum, Transactions and Studies of the College of Physicians of Philadelphia 43 (1975) 78-82.

3. H.N. Wardle, Description of a tsantsa in the ethnological collection of the academy, with notes on another specimen. Academy of Natural Sciences 66 (1) (1914) 197-205.

4. N. Lynnerup, Mummies, Yearbook of Physical Anthropology 50 (2007) 162-90.

5. M.A. Verhoff, C. Witzel, K. Kreutz, F. Ramsthaler, The ideal subject distance for passport pictures, Forensic Science International 178 (2008), 153-6.

$247_{16}$

48. Fujifilm, UV/IR Digital Camera Technology, Fujifilm corporation, 2007.

$259^{4}$

. S.M.F.M. De Souza, M. Fátima, K. Reinhard, A. Araújo, The Jivaro shrunken heads from the National Museum, Rio de Janeiro, Brazil: Authentic of Counterfeits? In: V World Congress on Mummy Studies, 2005, Turin. Journal of Biological Research. Turin : Societa Italiana di Biologia Experimentale LXXX (2005) 129-131.

8. Forensic Science Communications (FSC), Forensic Human Hair Examination Guidelines: Scientific Working Group on Material Analysis (SWGMAT), Forensic Science Communications, U.S. Department of Justice, Federal Bureau of Investigation 2 (3) (2005) 1-32.

. G.M. Roe, R. Cook, C. North, An evaluation of mounts for use in forensic hair examination, Journal of the Forensic Science Society 31 (1) (1991) 59-65. 
20. J.B. Ambrosetti, Las grandes hachas ceremoniales de la Patagonia. Anales del Museo Argentino de Ciencias Naturales III (1903) 45-51, Buenos Aires.

21. R. Karsten, The Headhunters of Western Amazonas, Societas Scientiarum Fennica, Commentations Humanarum 1 Litterarum, VII, 1, Helsingfors - Centraltryckeriet, 1935.

2

322. M. Dempsey, Hide, Skin and Leather Defects: A Guide to their Microscopy, A Lasra Publication, New Zealand 4
5 Leather and Shoe Research Association, Swiftcopy Centre Ltd, 1984.

723. J.J Tancous, Skin, Hides and Leather Defects, Leather industries of America laboratory, 1992.

824. R.C. Vreeman, A.E. Carroll, Medical Myths, British Medical Journal 335 (2007) 128.

10

41 1125. U. Blume, J. Ferracin, M. Verschoore, J.M. Czernielewski, H. Schaefer, Physiology of the vellus hair follicle: Hair 4212 growth and sebum excretion, British Journal of Dermatology 124 (1991) 21-28.

43 1426. N. Otberg, H. Richter, H. Schaefer, U. Blume-Peytavi, W. Sterry, J. Lademann, Variations of Hair Follicle Size and 44 Distribution in Different Body Sites, Journal of Investigative Dermatology 122 (2004) 14-19.

45 1827. A. Pagnoni, A.M. Kligman, S. El Gamma, T. Stoudemayer, Determination of density of follicles on various regions of 19 the face by cyanoacrylate biopsy: correlation with sebum output, British Journal of Dermatology 131 (6) (1994) 862-5.

. L. Rudnicka, A. Rakowsk, M. Olszewska, M. Slowinska, J. Czuwara, M. Rusek, A.M.C. Pinheiro, Atlas of Trichoscopy, Dermoscopy in Hair and Scalp Disease, Springer-Verlag London, 2012, 11-46.

19 2529. J. Kemble, Surgery for Nurses, Bristol, John Wright and sons Ltd, 1949, 106.

K. Edwards, B. Housekeeper, Serious Sportsman Taxidermy for Beginners: Introduction to taxidermy and deer foot projects 1-9, B. Publications, Inc. Pennsylvania State University, 1991.

N. Robinson, R.P. Evershed, W.J. Higgs, K. Jerman, G. Eglinton, Proof of a Pine Wood Origin for Pitch from Tudor (Mary Rose) and Etruscan Shipwrecks: Application of Analytical Organic Chemistry in Archaeology, Analyst 112 (1987) 637-644.

. J. Jones, T.F.G. Higham, R. Oldfield, T.P. O'Connor, S.A. Buckley, Evidence for Prehistoric Origins of Egyptian Mummification in Late Neolithic Burials, PLoS ONE 9 (8) (2014) e103608.

$57 \quad 39_{33}$

58

3. P. Carminati, A. Begerock, H. Gill-Ferking, Surface Treatment of Mummies: Mummification, Conservation or Beatification, Yearbook of Mummy Studies 2 (2014) 159-66.

59 4334. R. Karsten, The Civilization of the South American Indians, London: Kegan Paul, Trench, Turner and Co., Ltd, 1926. 44

50 4535. T.W. Whiffen, The North West Amazons, London: Constable and Company Ltd, 1915.

B. Arriaza, N.C. Orellana, H.S. Barbosa, R.F.S. Menna-Barreto, A. Araújo, V. Standen, Severe head lice infestation in an Andean mummy of Arica, Chile, International Journal of Parasitology 98(2) (2012) 433-6.

50

T. Ahir, The Trichology Society: Pediculosis humanus, www.hairscientists.org/head-lice, accessed: 14 July 2014.

B. Adam, A.T. Soo-Hoo, K.C. Chong, Black piedra in West Malaysia, Australian Journal of Dermatology 18 (1977) 18:45-7.

565639 57

9.S. De Hoog, J. Guarro, J. Gené, M.J. Figueras, Atlas of Clinical Fungi, CBS, Universitat Rovira i Virgili, 2005.

D. Larone, Medically Important Fungi, ASM Press, Washington DC, 1995.

D. Carrion, J. Vasconez, N. Bermudez, The case of Quito, Ecuador, Centro de Investigaciones de Ciudad, Fernando Meneses \#265 y Av. la Gasca, Quito, Ecuador 1708-8311 (2005) 1-24. 
70

71

72

1

2

3

4

5

6

7

8

9

10

11

12

13

14

15

16

17

18

19

20

21

22

23

24

25

26

27

28

29

30

31

32

33

34

35

36

37

38

39

40

41

42

43

44

45

46

47

48

49

50

51

52

53

54

55

56

57

58

59

60

61

62

63

64

65

\begin{abstract}
A. Kern, J. Ritzen, Dying for change: Poor people's experience of health and ill health, Sustainable Development and Healthy Environments, 2005, World Health Organisation, www.who.int/hdp/publications/dying_change.pdf, accessed:
\end{abstract} 14 July 2014. 


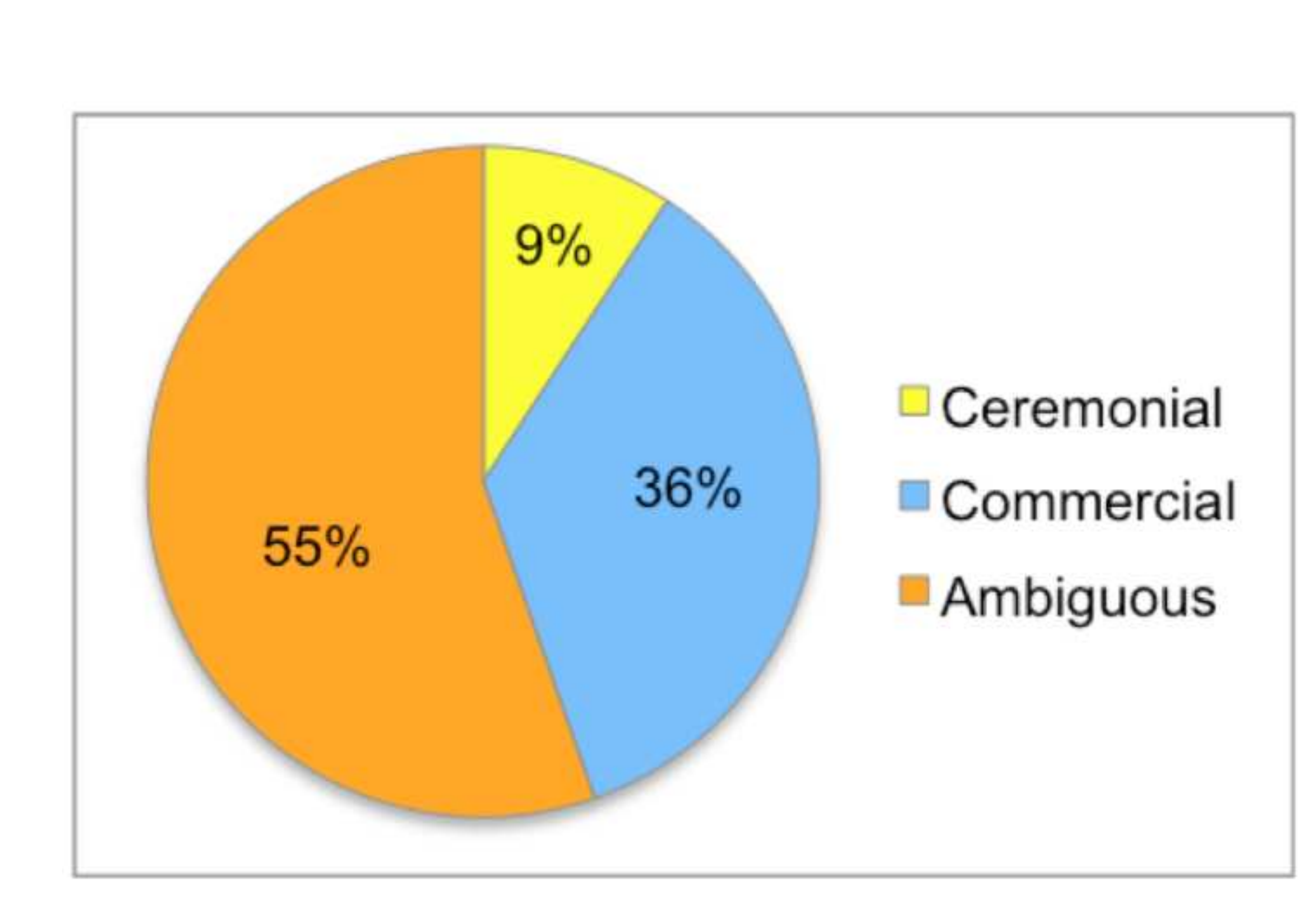

$\square$ Ceremonial

Commercial Ambiguous

$55 \%$

$9 \%$

$36 \%$ 


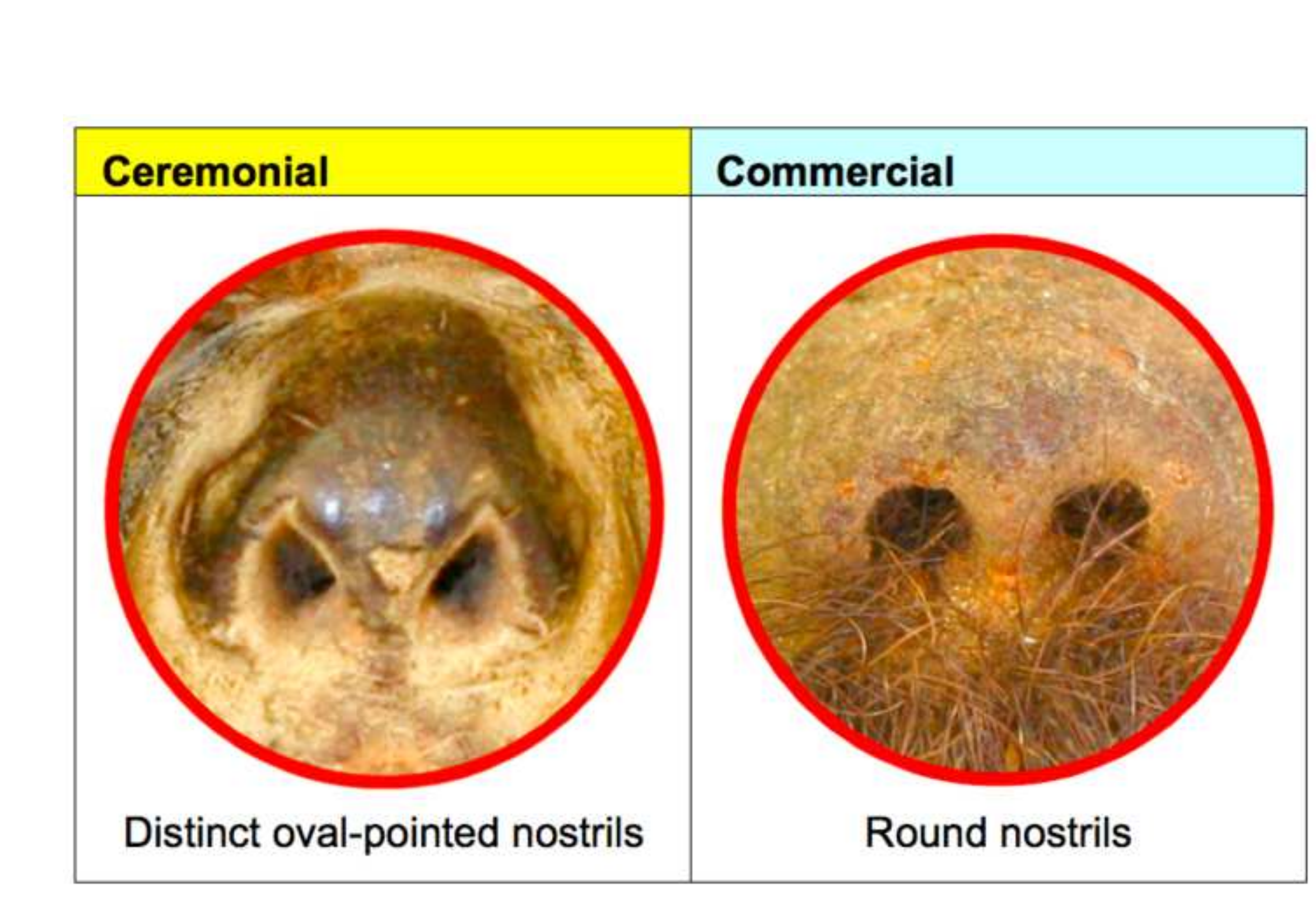

(1)
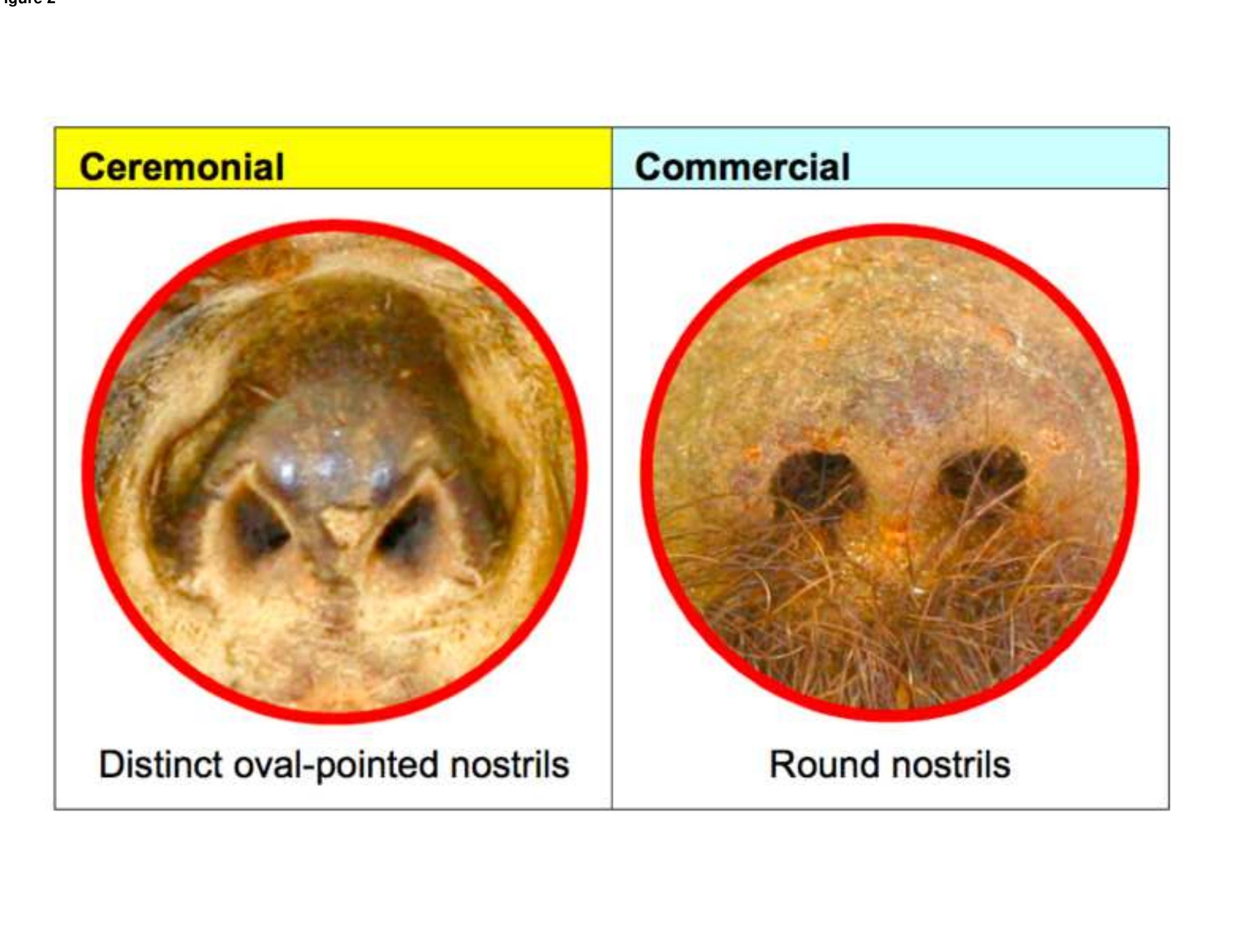


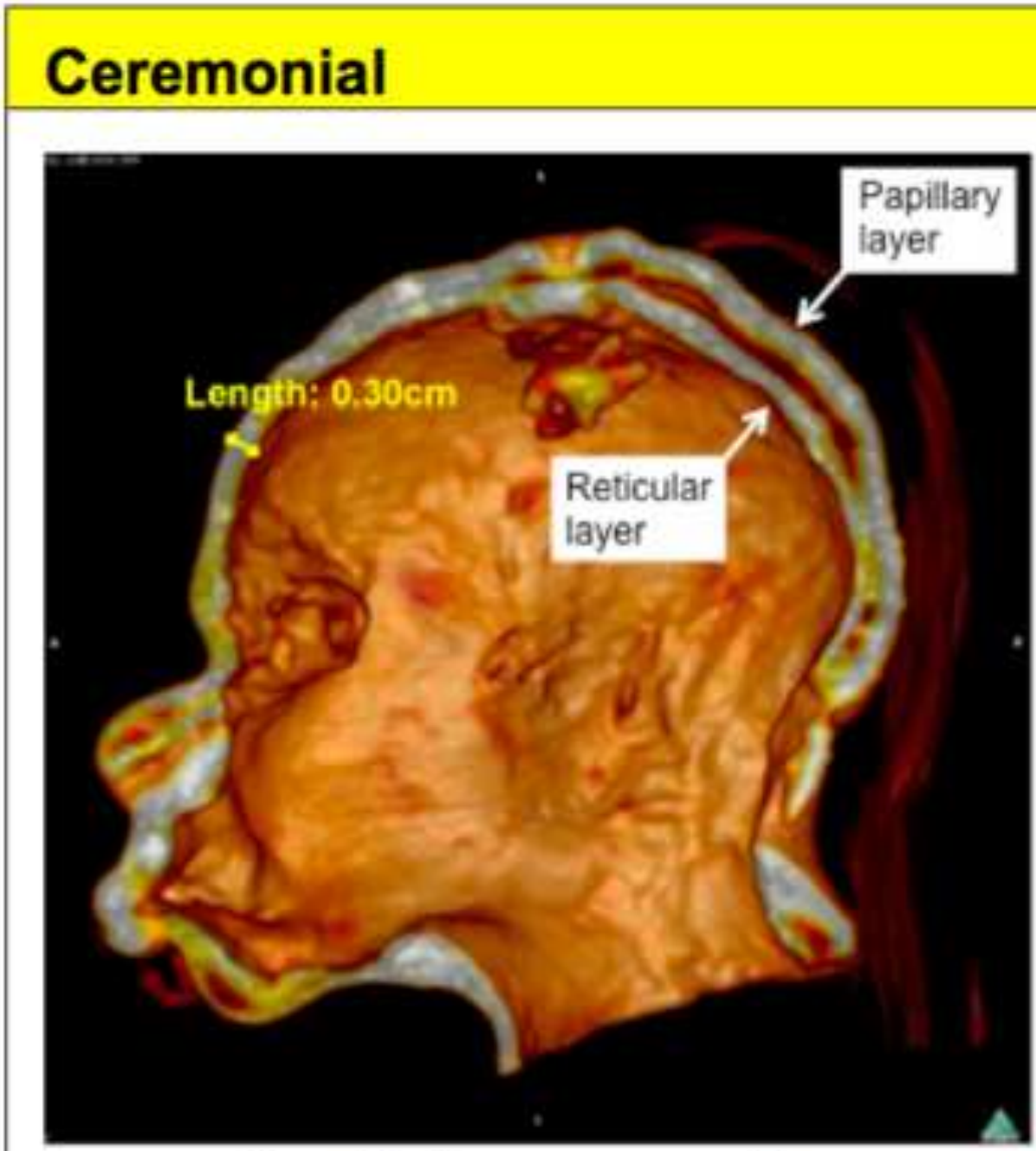

Sagittal cross section (lateral view)

\section{Commercial}

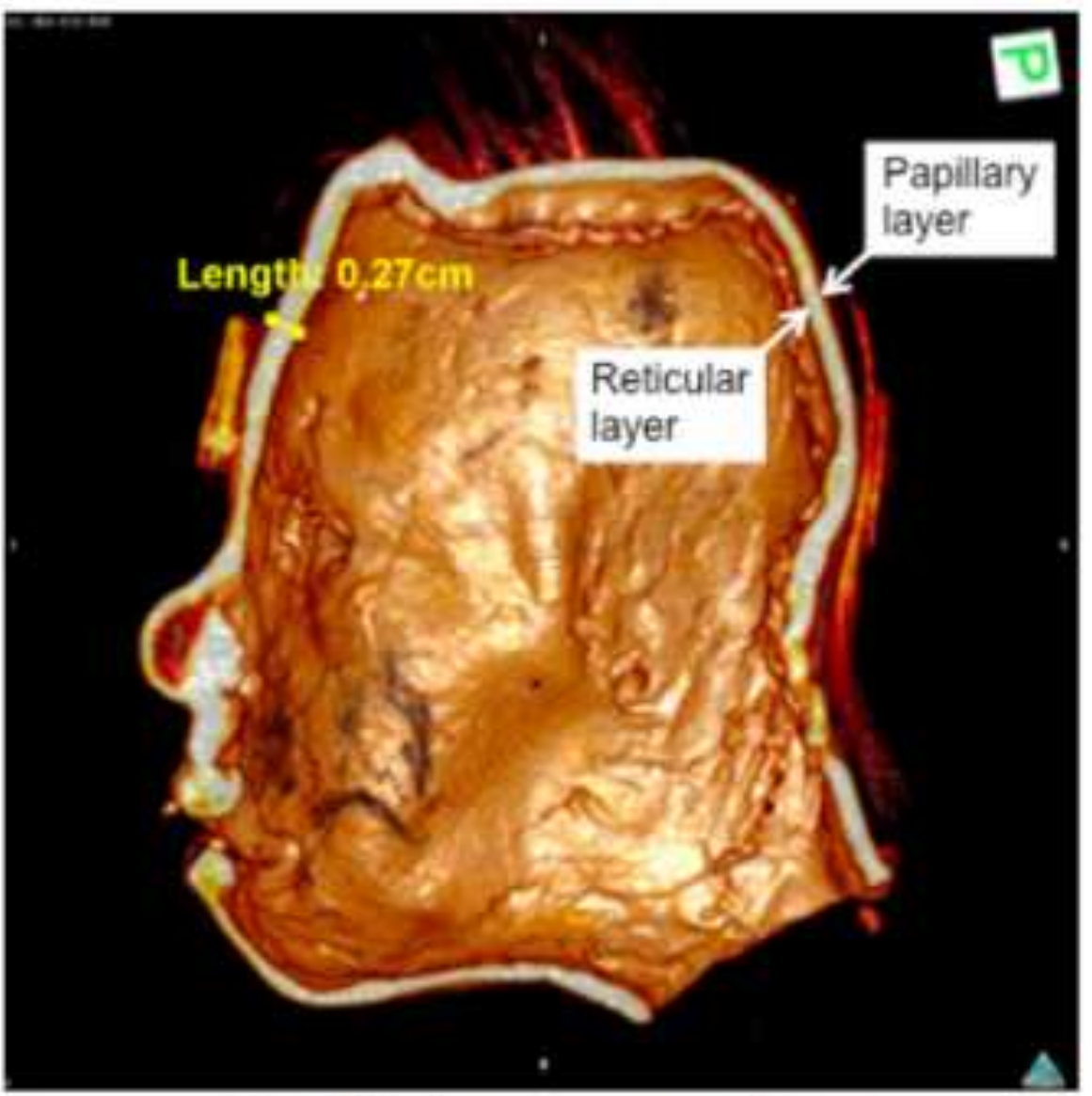

Sagittal cross section (lateral view) 


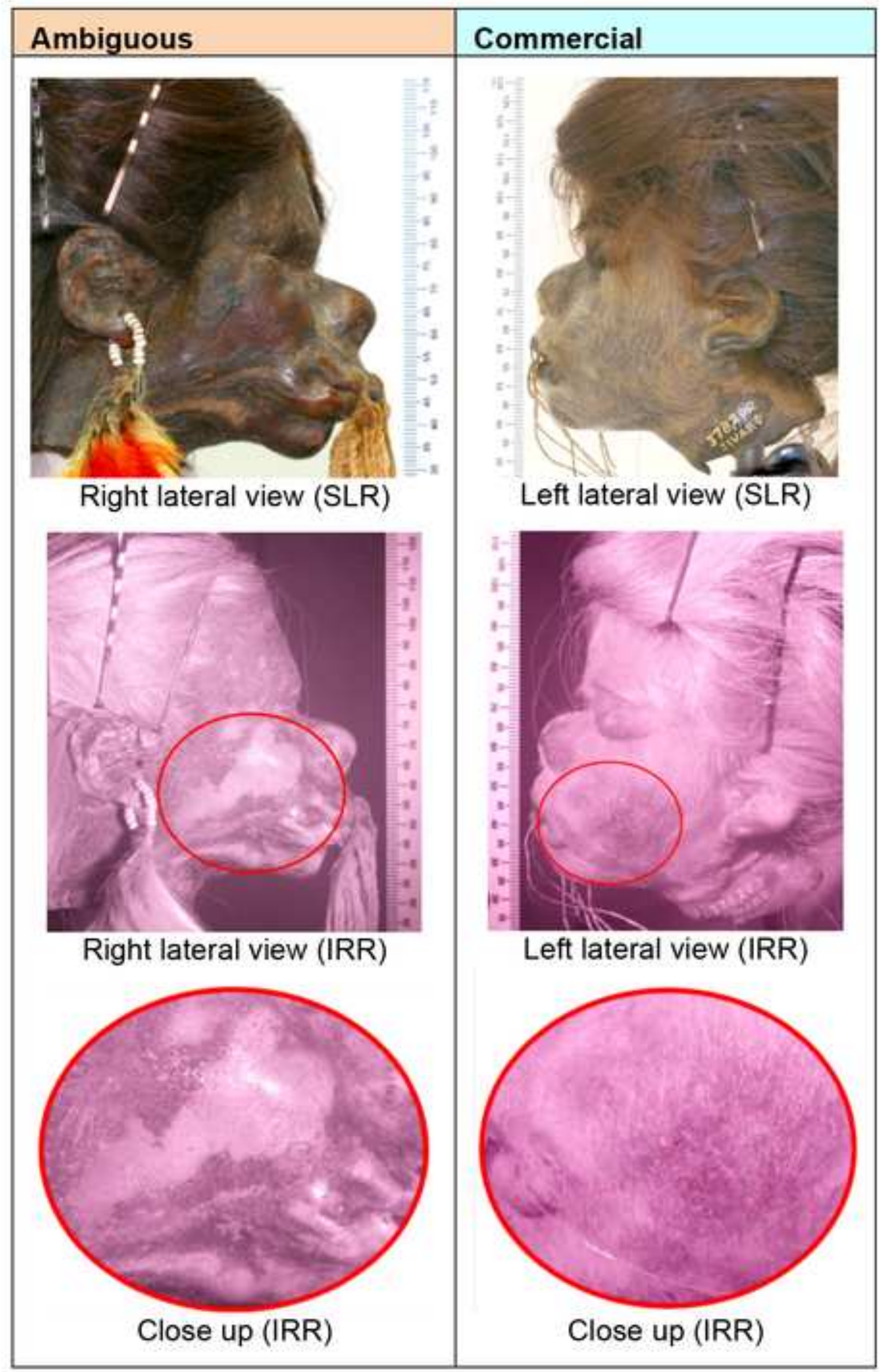




\section{Commercial}

Grey-white epidermis

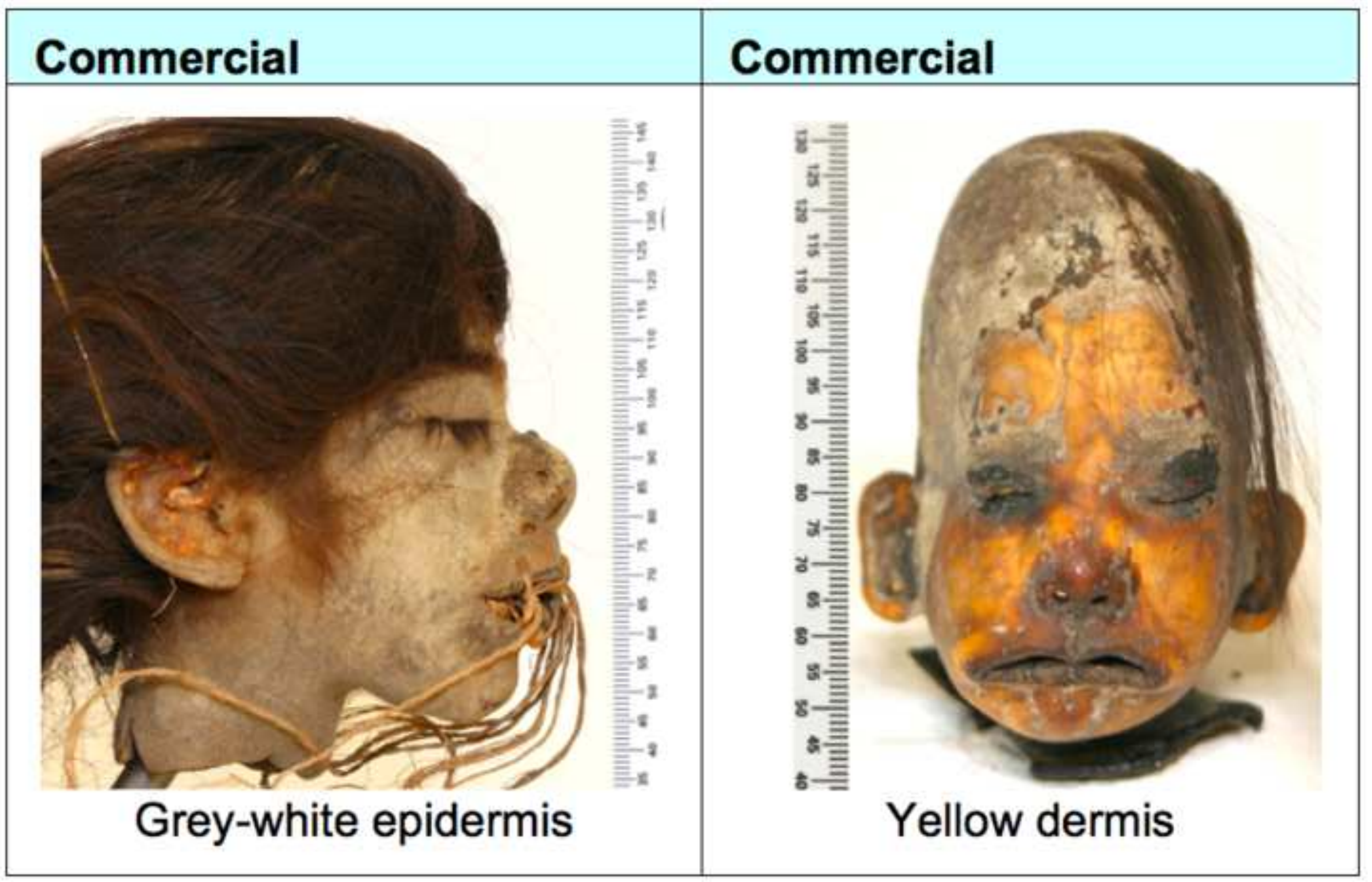

\section{Commercial}

Yellow dermis
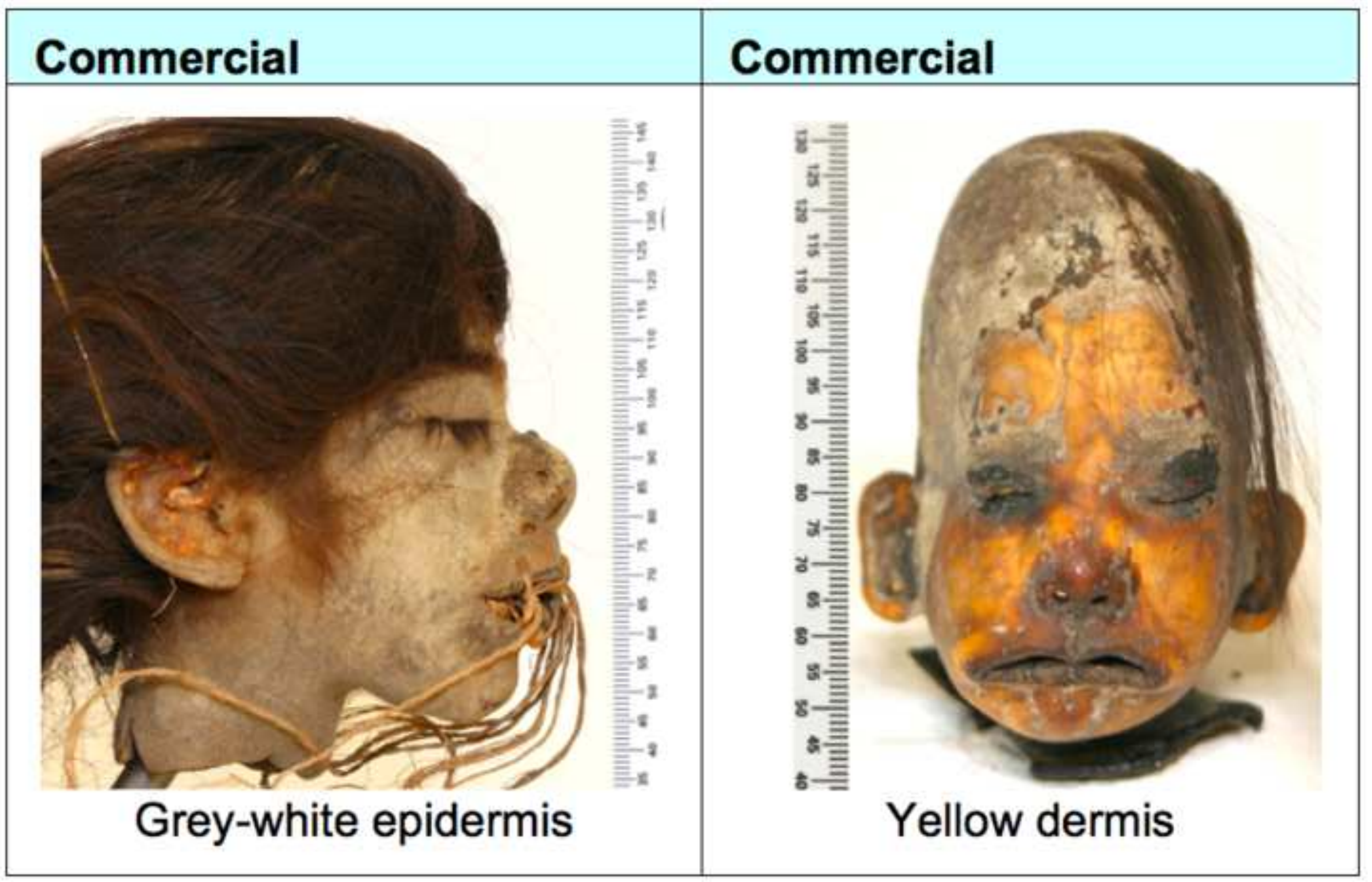


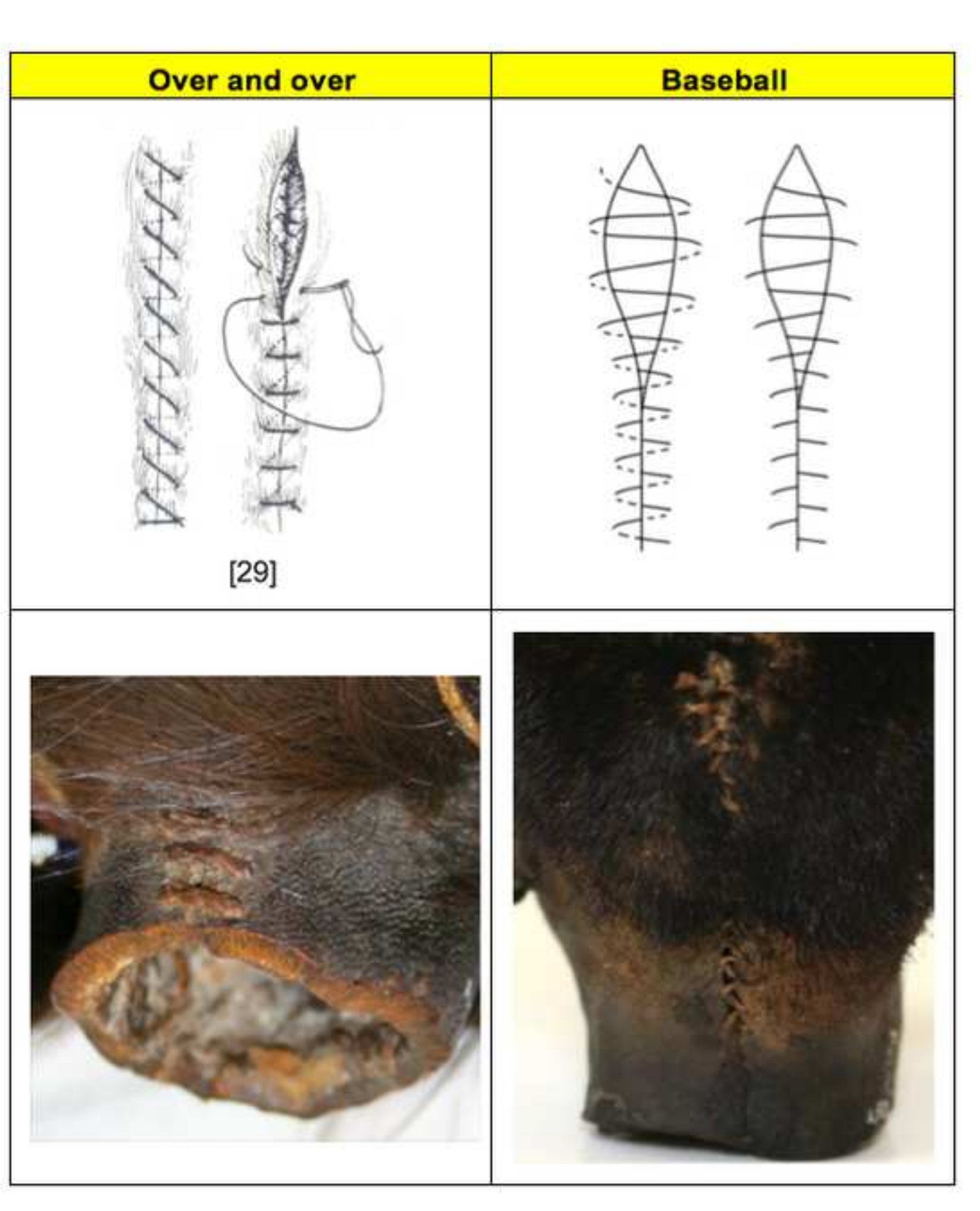

Figure 6

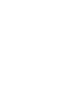

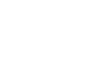

Fure

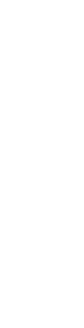




\section{Ceremonial}

Straight incision, smooth edge

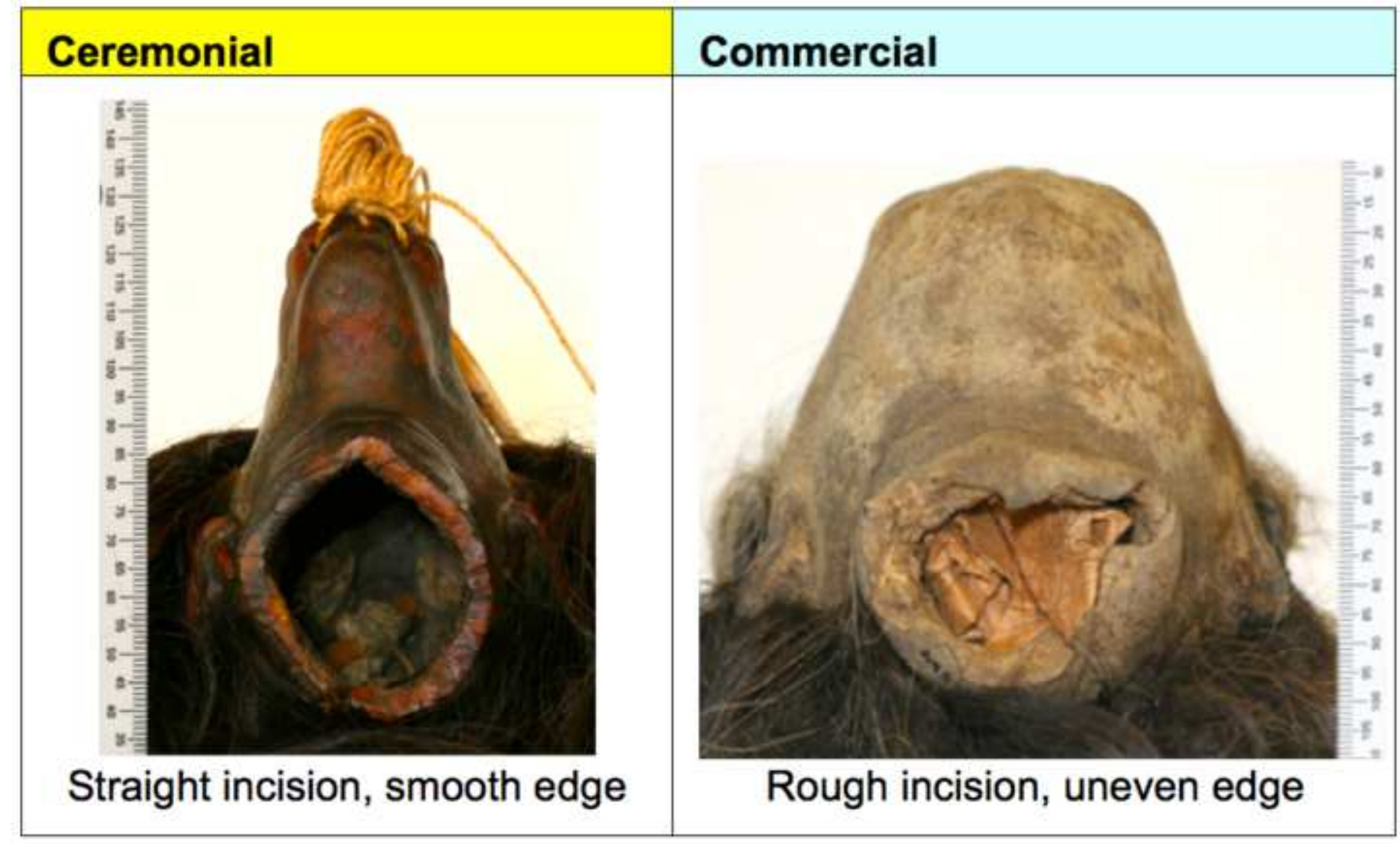

\section{Commercial}

Rough incision, uneven edge

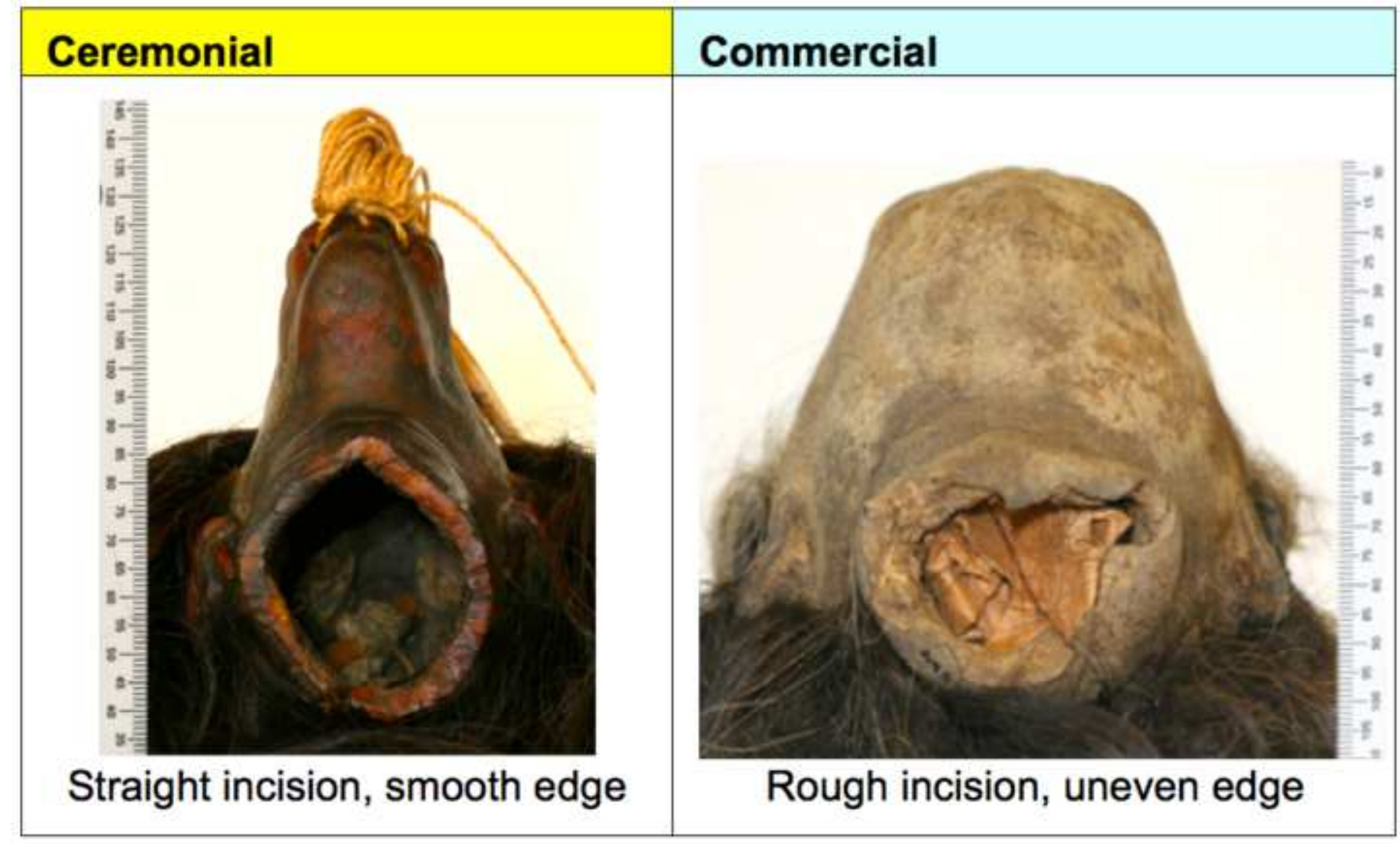




\section{Ceremonial}

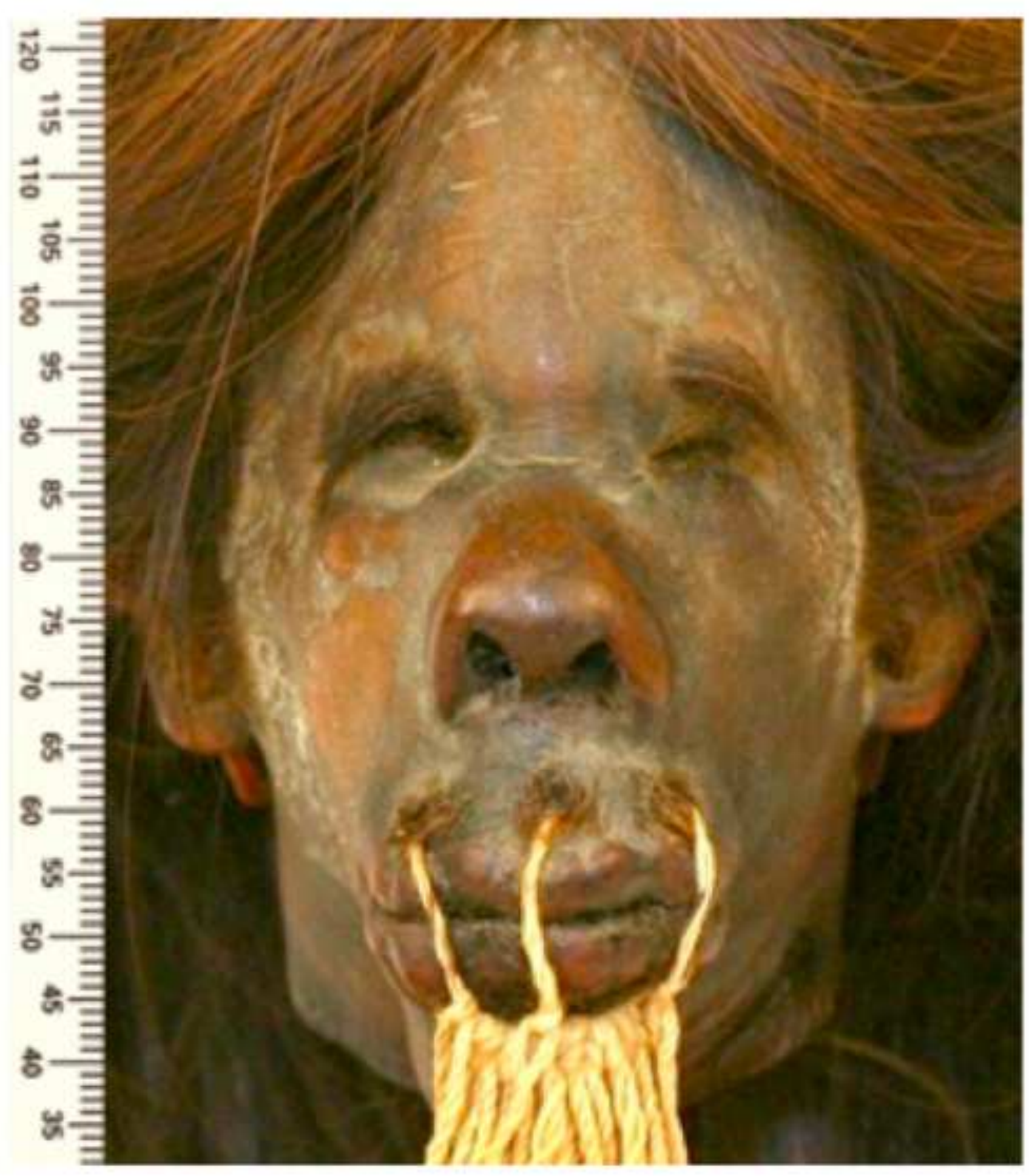

Figure 8

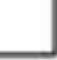

洒

$\vec{n}$

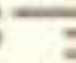

= 


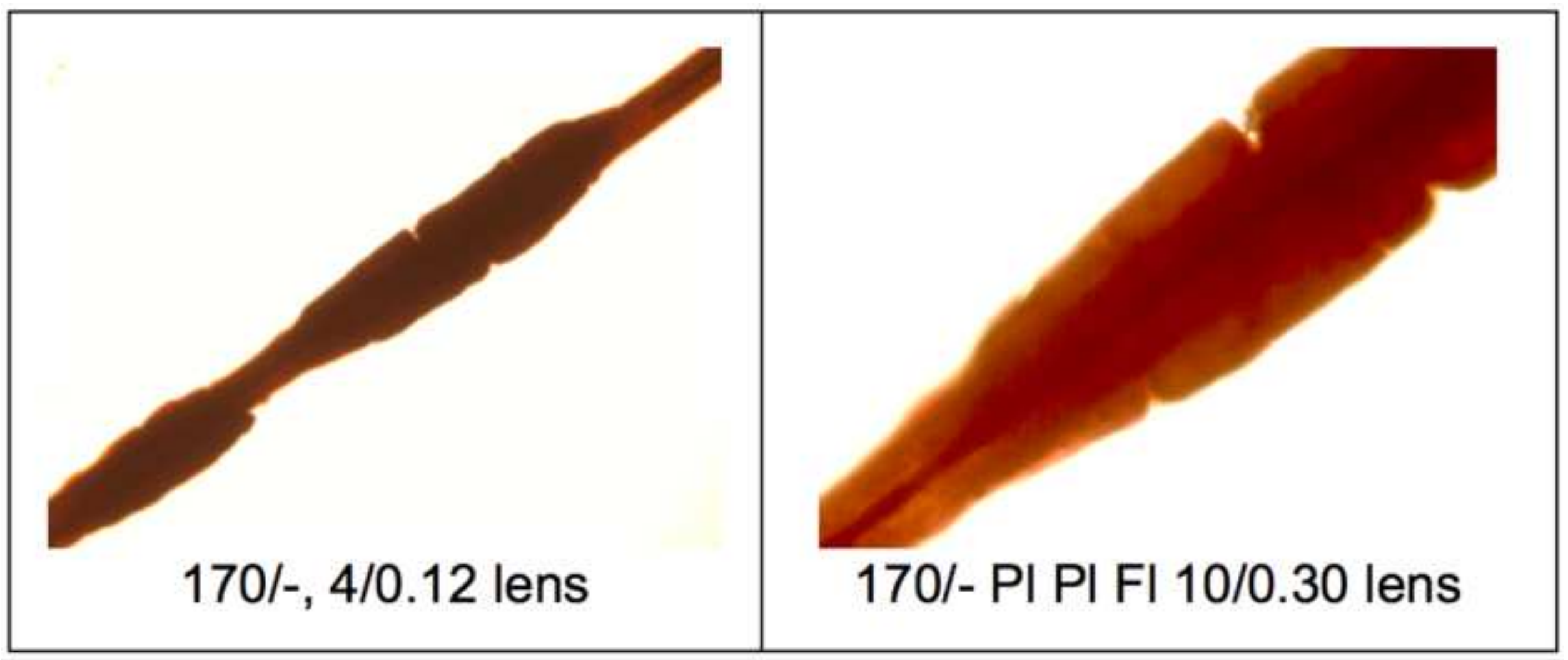


Figure 10

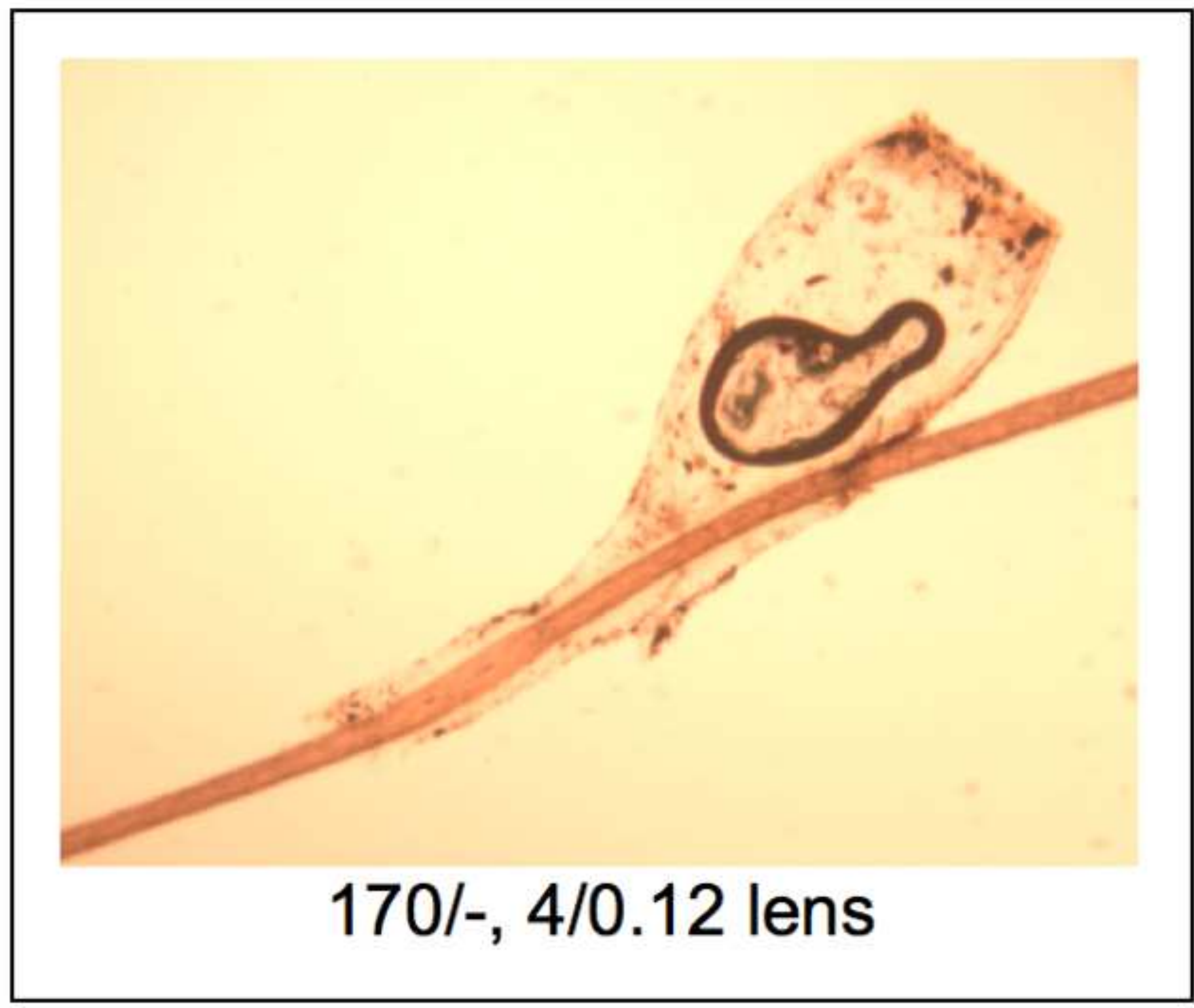

